\title{
Congenital Malformations in Infants of Mothers Undergoing Assisted Reproductive Technologies: A Systematic Review and Meta-analysis Study
}

\author{
Hayedeh Hoorsan', Parvin Mirmiran², Shahla Chaichian ${ }^{3}$, Yousef Moradi ${ }^{4}$, Roza Hoorsan $^{5}$, Fatemeh Jesmi ${ }^{6}$ \\ ${ }^{1}$ Department of Nursing and Midwifery, Islamic Azad University Sanandaj Branch, Sanandaj; ${ }^{2}$ National Nutrition and Food Technology Research \\ Institute, Faculty of Nutrition Sciences and Food Technology, Shahid Beheshti University of Medical Sciences, Tehran; ${ }^{3}$ Minimally Invasive Techniques \\ Research Center in Women, Islamic Azad University Tehran Medical Branch, Tehran; ${ }^{4}$ Department of Epidemiology, School of Public Health, Shahid \\ Beheshti University of Medical Sciences, Tehran; ${ }^{5}$ Department of Nursing and Midwifery, Islamic Azad University Tehran Medical Branch, Tehran; \\ ${ }^{6}$ Pars Advanced and Minimally Invasive Medical Manners Research Center, Pars Hospital, Iran University of Medical Sciences, Tehran, Iran
}

Objectives: This meta-analysis aimed to evaluate congenital malformations in infants conceived by assisted reproductive techniques (ART), compared with infants conceived spontaneously.

Methods: In this study, available resources searched to find relevant articles included PubMed, ScienceDirect, Scopus, Google Scholar, Cochrane, ProQuest, Iranmedex, Magiran, and Scientific Information Database. After extracting the necessary information from evaluated articles, meta-analysis on the articles' data was performed using Stata version 11.2.

Results: In this study, from a total of 339 articles, extracted from the initial investigation, ultimately 30 articles were selected for metaanalysis that assessed the use of ART on the risk of congenital abnormalities and some birth complications on 5470181 infants (315 402 cases and 5154779 controls). The odds ratio (95\% confidence interval [CI]) for low birth weight was 1.89 (95\% Cl, 1.36 to 2.62), preterm labor $1.79(95 \% \mathrm{Cl}, 1.21$ to 2.63), cardiac abnormalities $1.43(95 \% \mathrm{Cl}, 1.27$ to 1.62$)$, central nervous system abnormalities $1.36(95 \% \mathrm{Cl}, 1.10$ to 1.70$)$, urogenital system abnormalities $1.58(95 \% \mathrm{Cl}, 1.28$ to 1.94$)$, musculoskeletal disorders $1.35(95 \% \mathrm{Cl}, 1.12$ to 1.64), and chromosomal abnormalities in infants conceived by ART was $1.14(95 \% \mathrm{Cl}, 0.90$ to 1.44$)$, which were all statistically significant, except chromosomal abnormalities.

Conclusions: The risk of congenital abnormalities and some birth complications were significantly higher in ART than normal conception, while chromosomal abnormalities were not; therefore, the application of ART should be selected individually for patients by detailed assessment to reduce such risks in the population.

Key words: Assisted reproductive technologies, Intracytoplasmic sperm injection, In vitro fertilization, Meta-analysis

Received: December 27, 2016 Accepted: June 20, 2017

Corresponding author: Shahla Chaichian, MD, PhD

Khaghani St., Shariati Ave., Tehran 193951495, Iran.

Tel: +98-218-895-2035, Fax: +98-218-898-9690

E-mail: shchaichian@gmail.com

This is an Open Access article distributed under the terms of the Creative Commons Attribution Non-Commercial License (http://creativecommons.org/licenses/bync/4.0/) which permits unrestricted non-commercial use, distribution, and reproduction in any medium, provided the original work is properly cited.

\section{INTRODUCTION}

Assisted reproductive technologies (ART) include $1 \%$ of births in the US and $4.3 \%$ of births in European countries and Australia [1]. Scientific and medical advances have increased the pregnancy rates and births following ART can be expected to rise. Any method or medication to achieve pregnancy is accepted as a broad definition of the concept of ART, which in- 
cludes ovulation induction, intrauterine insemination, in vitro fertilization (IVF), and intracytoplasmic sperm injection (ICSI) [2]. Application of these methods has solved the infertility problem of human and had multiple health benefits for millions of couples suffering from fertility problems [3]. During the past 36 years, ART has reformed from a miracle to a standard and common part of medical practice. More than 200000 infants are annually born worldwide by this technology [2]. It is estimated that over 5 million children worldwide have been born after ART procedures [1]. There are worldwide 72.4 million infertile women and $21-22 \%$ of women in our country experience primary infertility in their marital life. Worldwide, about 40 million couples benefit from reproductive medicine $[4,5]$. All these figures indicate that since the birth of Louise Brown, the first baby born after artificial insemination in 1978 in the UK, ART have advanced quickly that have attracted more and more researcher's attention towards the risks and complications of this method [6]. Developed and advanced use of this method has increased the rate of infants born by this method and have pursued researchers to follow these children's health status [7].

After 30 years of using ART, there are evidence of increased adverse perinatal outcomes such as premature birth (PTB), low birth weight (LBW) and small for gestational age infants, compared with children conceived spontaneously [8]. Studies show that ART can increase the incidence of congenital malformations at $25-40 \%$ [9] and these children are at risk of a range of disabilities [10].

Various artificial methods, performed during ART treatment, imply the concern that infants conceived through these methods are at higher risk than infants conceived spontaneously. In such methods, firstly, many drugs are prescribed to stimulate ovulation, oocyte retrieval, and embryos cultured, frozen and melt in vitro, and high doses of progesterone for luteal phase support, which may all damage gametes or embryos. In addition, ICSI method, in which an egg is fertilized by injecting sperm directly into ooplasm, is considered more invasive than IVF. It also significantly increases the risk of multiple pregnancies by transferring more than one embryo, which leads to risk of complications such as PTBs and LBW [3].

The results of some studies indicate that infants conceived through ART are at higher risk of congenital abnormalities than normal pregnancies, but some other studies have not observed such difference or have even reported less risk, especially in multiple pregnancies [6].
Regarding the conflicting results and as far as some complications can cause malformations that increase in infants conceived through this method, such as preterm labor and LBW, thus, this meta-analysis study aimed to assess the complications and the risk of some congenital malformations including cardiovascular, central nervous system, musculoskeletal, urogenital and chromosomal abnormalities in newborns conceived following ART compared to infants conceived spontaneously.

\section{METHODS}

In this study, available resources searched to find relevant articles included PubMed, ScienceDirect, Scopus, Google Scholar, Cochrane, ProQuest, Iranmedex, Magiran, and Scientific Information Database (SID) databases, published from 2005 to 2015. We retrieved 201 citations in PubMed, 38 citations in Scopus, 55 citations in EMBASE, 10 citations in Google Scholar, 15 citations in Cochrane, 16 citations in ProQuest, 4 citations in Iranmedex, 0 citation in Magiran and 0 citation in SID.

In order to avoid losing resources, congress performances, theses, books and other domestic and foreign valid websites were manually searched. List of references used in all articles and related reports found by the electronic search were evaluated manually to include other possible sources in the study.

The searched keywords included (birth defect or congenital malformation or congenital abnormalities) and (ART or IVF or ICSI). After preparation of the initial list, two colleagues examined titles and abstracts independently and identified relevant articles. Then, they registered closely-related or possibly-related studies and selected related studies by examining the full text of articles. At the end, among the articles selected based on critical evaluation, articles that met the inclusion criteria were finally selected (Table 1).

To include the study objectives, all articles with the following inclusion criteria were extracted: Access to full-text articles in English; Cohort or case-control studies; The study population including infants conceived through ART vs. control group over a period of time.

\section{Data Extraction and Quality Evaluation}

All identified papers were critically appraised independently by two reviewers (SC and YM). Any disagreement was assessed by both and if a consensus was not reached, a third author $(\mathrm{HH})$ evaluated the study. Two independent matched reviewers (PM 
and YM) extracted data according to a uniform Excel sheet. Disagreements between reviewers were resolved by consensus. Appraisal was guided by checklist assessing clarity of the aims and research questions. STROBE (Strengthening the Reporting of Observational Studies in Epidemiology) checklist score was used as a standard checklist for reporting the results of the included studies. Then, the closely-related or possibly-related studies were listed and selected by examining the full text of eligible articles. At the end, among selected articles, based on critical evaluation, articles that met the inclusion criteria were ultimately selected (Table 1). Some of the information, including odds ratio (OR) in some studies and confidence interval (Cl), $p$-value, number of samples extracted from the articles, the standard error, variance and the logarithm of the variance and weight of articles were calculated using available data in the literature.

\section{Data Analysis}

After extracting the necessary information from evaluated articles, meta-analysis on the articles' data was performed using Stata version 11.2 (StataCorp, College Station, TX, USA). Metan order was used to analyze the data, and Q-test and $\mathrm{I}^{2}$ were used to measure heterogeneity of studies and Begg's funnel plot to assess publication bias.

\section{RESULTS}

In this study, from a total of 339 articles extracted from the initial investigation, ultimately 30 articles were selected for meta-analysis tests that assessed the use of ART on the risk of congenital abnormalities and some birth complications on 5470181 infants (315 402 cases and 5154779 controls). All studies were evaluated by two independent researchers and, in case of disagreement, a third arbitrator examined to rule out the study.

Supplemental Tables 1 and 2 show the results of the metaanalysis, the OR for congenital malformations and birth complications among infants conceived through ART. The estimated OR for congenital abnormalities in infants conceived by ART was 1.53 ( $95 \% \mathrm{Cl}, 1.37$ to 1.70$)$, which was statistically significant. This means that infants conceived through ART are at $53 \%$ increased risk of congenital abnormalities than other infants. The results partly reflect the heterogeneity of the studies $\left(\chi^{2}=214.43 ; p<0.001 ; I^{2}=89.7 \%\right)$, but since the $\mathrm{Cl}$ of test (Egger's test) included zero, no significant bias occurred in the pub- lication of the results. The estimated OR for LBW in infants conceived by ART was 1.89 ( $95 \% \mathrm{Cl}$. 1.36 to 2.62), which was statistically significant. This means that infants conceived through ART are at $89 \%$ increased risk of LBW than other infants. The results partly reflect the heterogeneity of the studies $\left(\chi^{2}=2174.05 ; p<0.001 ; I^{2}=99.3 \%\right)$, but since the $\mathrm{Cl}$ of test (Egger's test) included zero, no significant bias occurred in the publication of the results.

The estimated OR for preterm labor in infants conceived by ART was 1.79 (95\% Cl, 1.21 to 2.63 ), which was statistically significant. This means that infants conceived through ART are at $79 \%$ increased risk of preterm labor than other infants. The results partly reflect the heterogeneity of the studies $\left(\chi^{2}=\right.$ 3089.90; $p<0.001 ;\left.\right|^{2}=99.6 \%$ ), but since the $\mathrm{Cl}$ of test (Egger's test) included zero, no significant bias occurred in the publication of the results (Table 2).

The estimated OR for cardiac malformations in infants conceived by ART was $1.43(95 \% \mathrm{Cl}, 1.27$ to 1.27$)$, which was statistically significant. This means that infants conceived through ART are at $43 \%$ increased risk of cardiac malformations than other infants. The results partly reflect the heterogeneity of the studies $\left(\chi^{2}=31.12 ; p=0.003 ; I^{2}=58.2 \%\right)$, but since the $\mathrm{Cl}$ of test (Egger's test) included zero, no significant bias occurred in the publication of the results (Table 2).

The estimated OR for central nervous system malformations in infants conceived by ART was $1.36(95 \% \mathrm{Cl}, 1.10$ to 1.70$)$, which was statistically significant. This means that infants conceived through ART are at 36\% increased risk of central nervous system malformations than other infants. The results partly reflect the heterogeneity of the studies $\left(\chi^{2}=25.67\right.$; $\left.p=0.002 ; I^{2}=64.9 \%\right)$, but since the $\mathrm{Cl}$ of test (Egger's test) included zero, no significant bias occurred in the publication of the results (Supplemental Table 2).

The estimated OR for urogenital malformations in infants conceived though ART was $1.58(95 \% \mathrm{Cl}, 1.28$ to 1.94), which was statistically significant. This means that infants conceived though ART are at 58\% increased risk of urogenital malformations than other infants. The results partly reflect the heterogeneity of the studies $\left(\chi^{2}=65.26 ; p<0.001 ;\left.\right|^{2}=81.6 \%\right)$, but since the $\mathrm{Cl}$ of test (Egger's test) included zero, no significant bias occurred in the publication of the results (Supplemental Table 2).

The estimated OR for musculoskeletal malformations in infants conceived by ART was $1.35(95 \% \mathrm{Cl}, 1.12$ to 1.64$)$, which was statistically significant. This means that infants conceived through ART are at 35\% increased risk of musculoskeletal mal- 


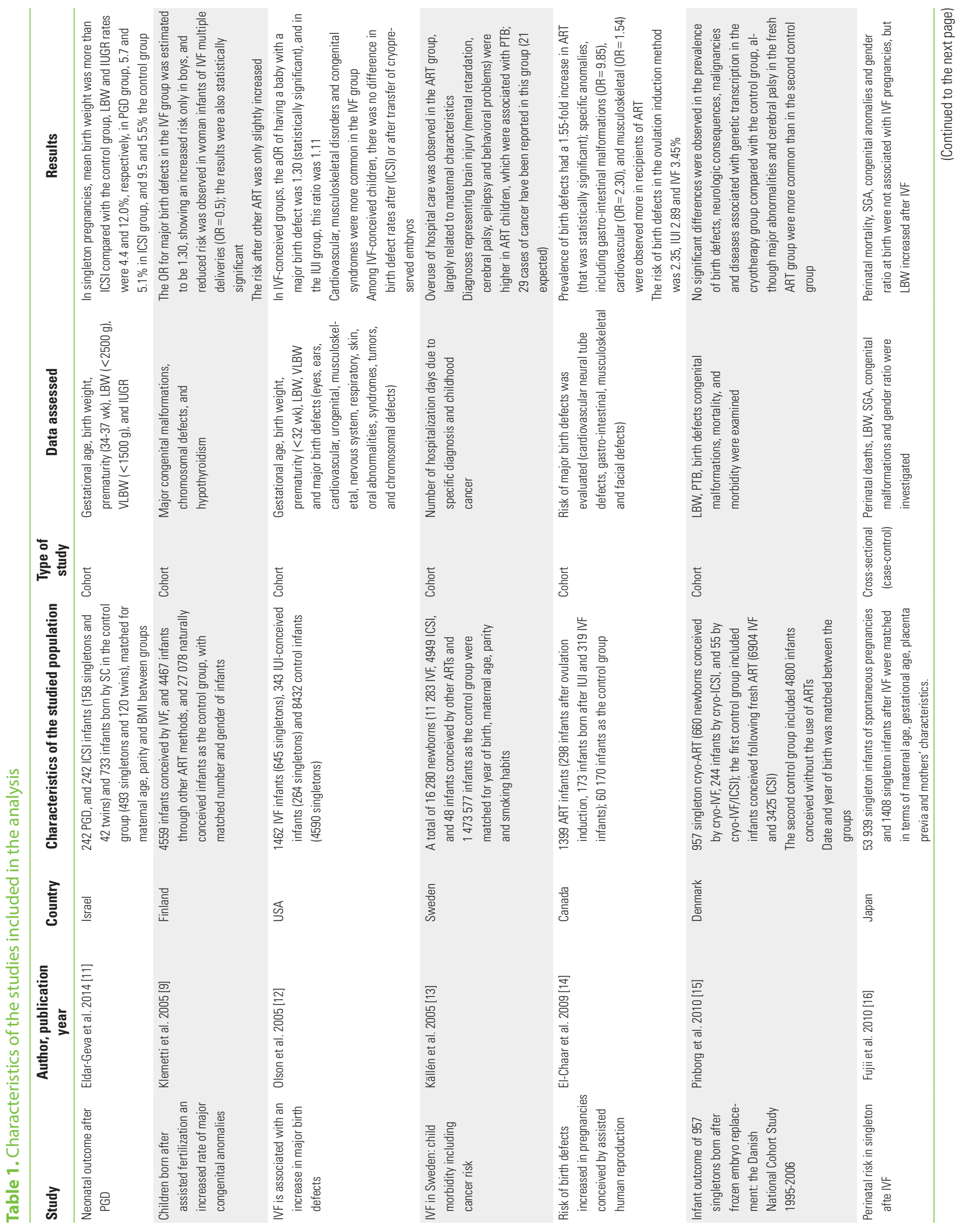



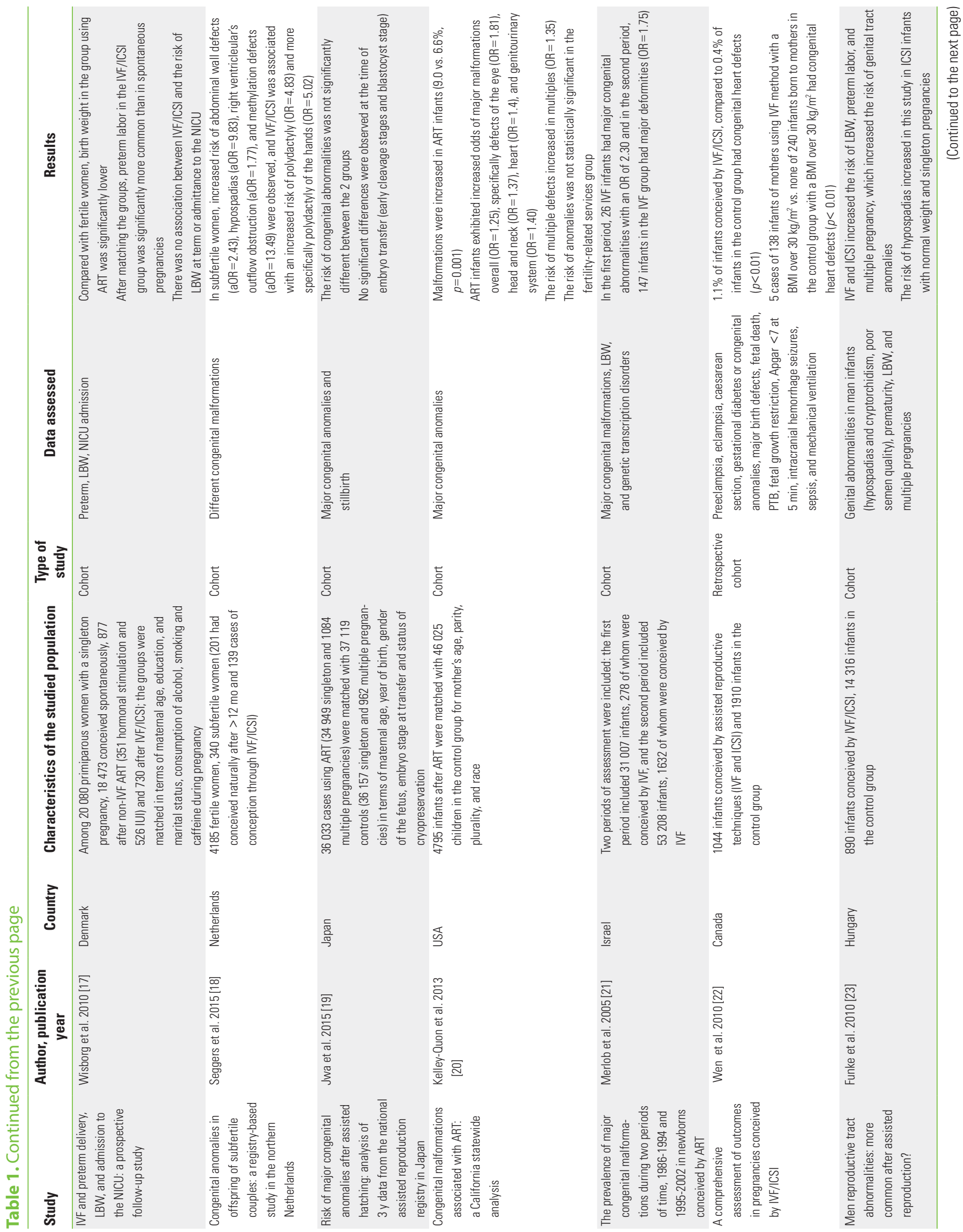


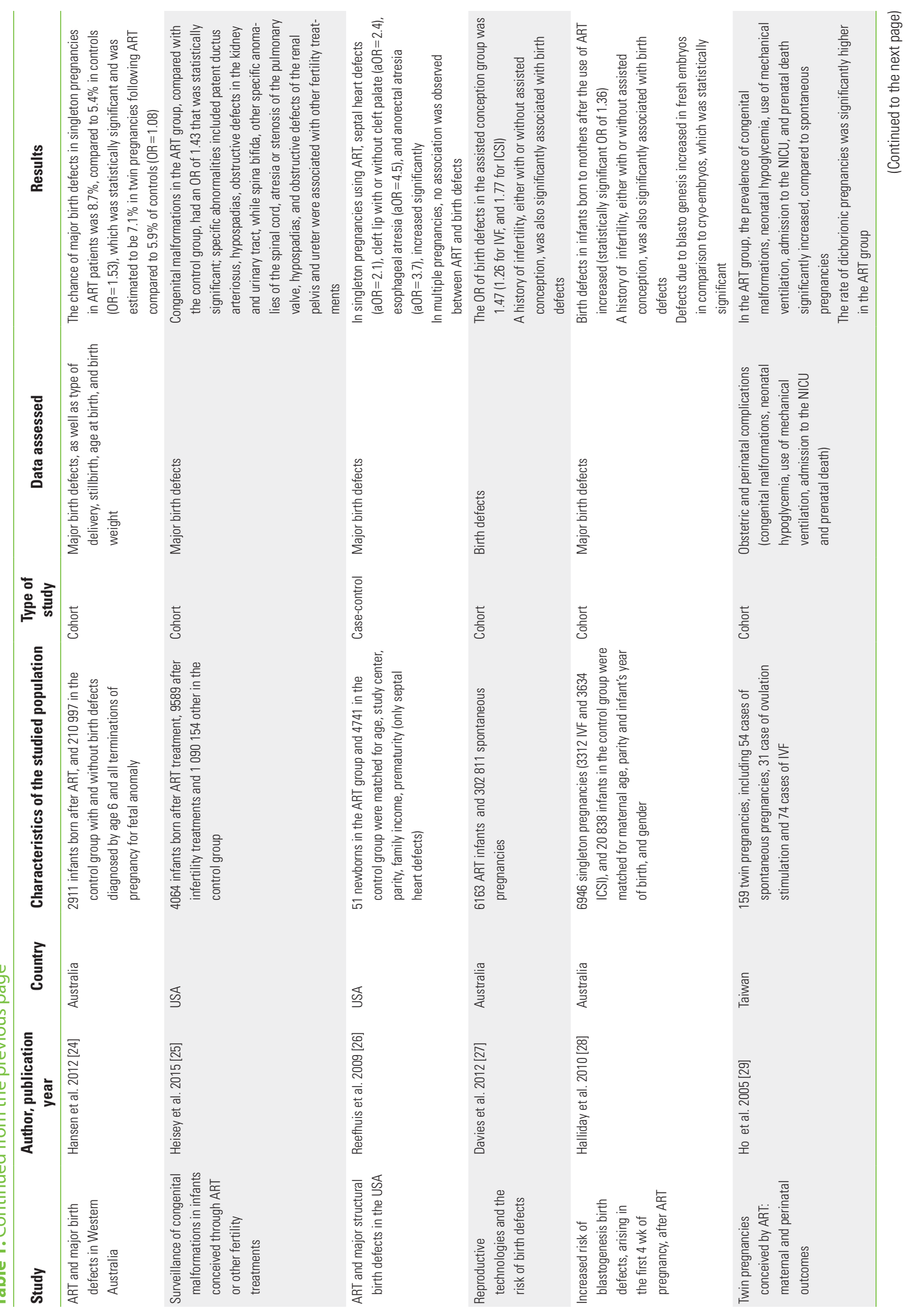




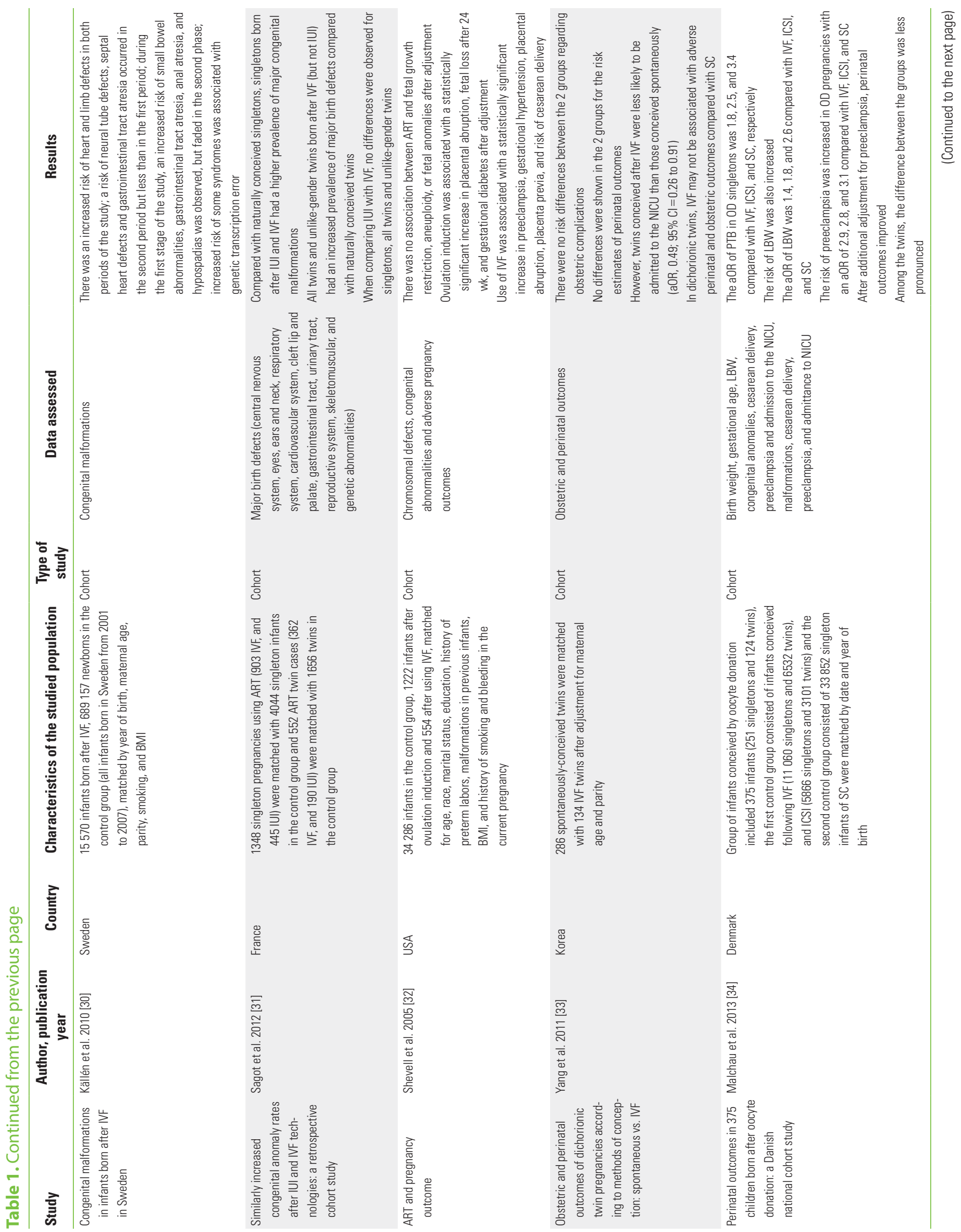




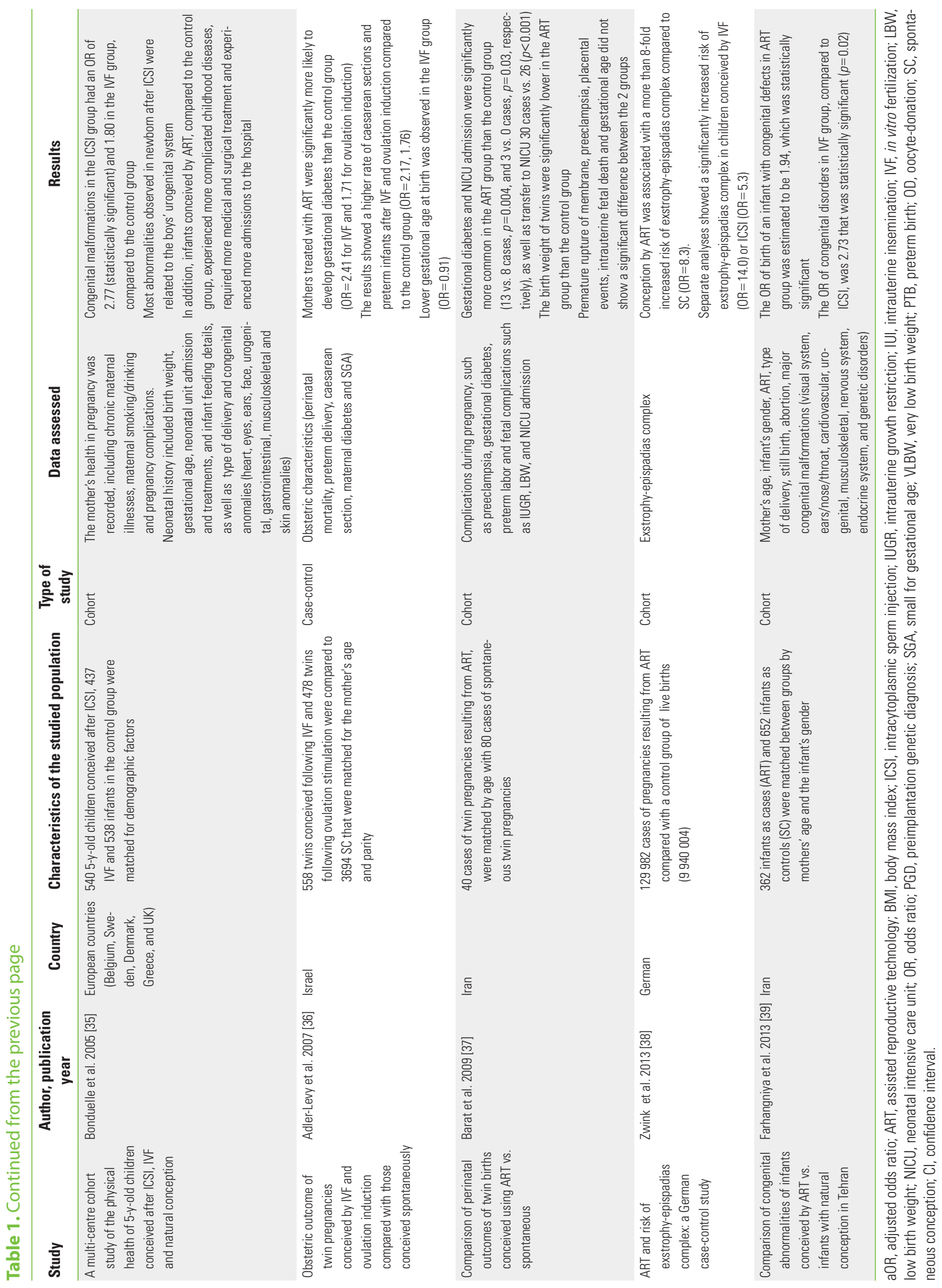


Table 2. Results of the meta-analysis of the odds of preterm labor and cardiovascular abnormalities in ART infants

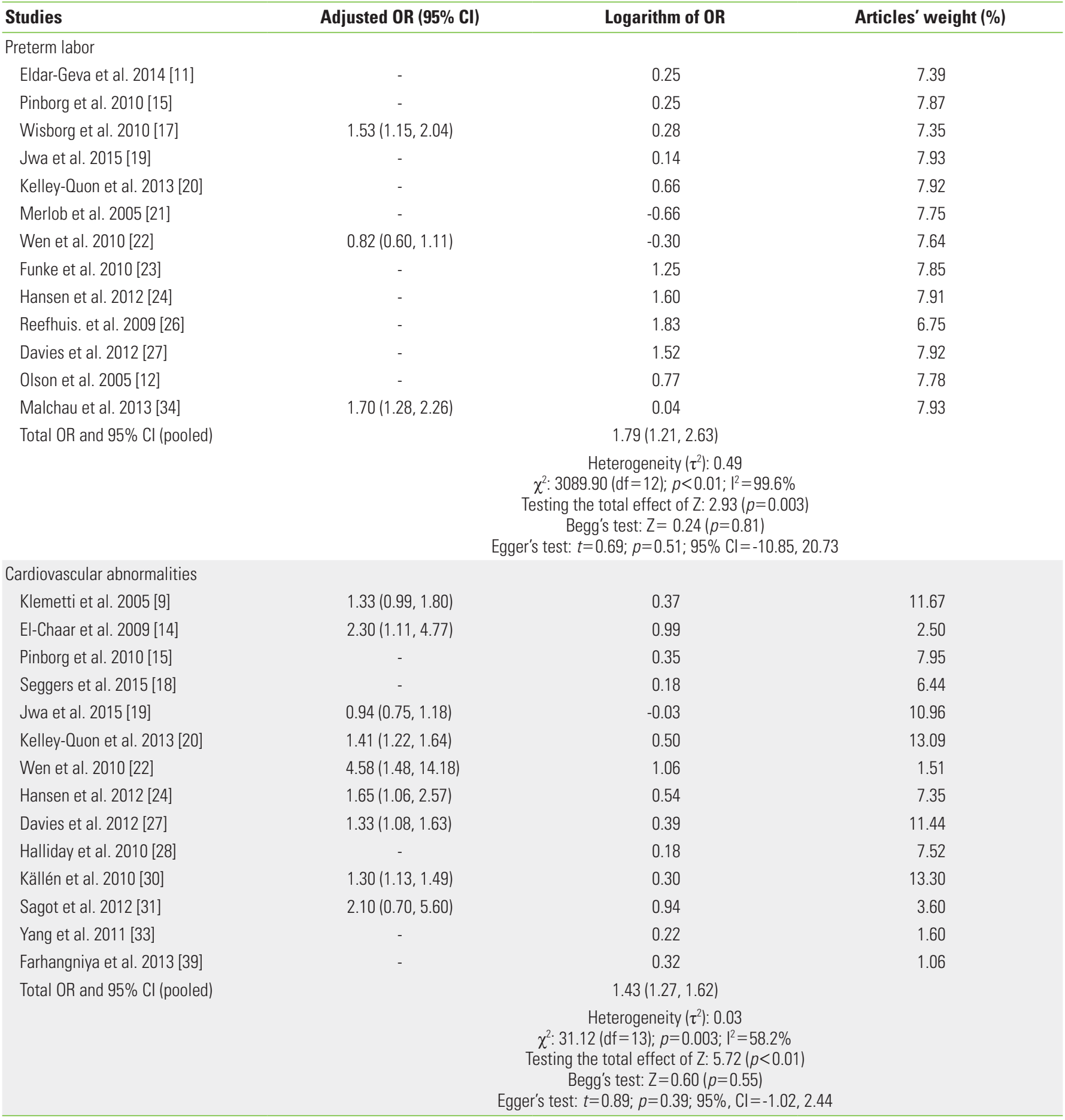

$A R T$, assisted reproductive technology; $\mathrm{OR}$, odds ratio; $\mathrm{Cl}$, confidence interval.

formations at $35 \%$. The results partly reflect the heterogeneity of the studies $\left(\chi^{2}=34.93 ; p<0.001 ; I^{2}=74.06 \%\right)$, but since the $\mathrm{Cl}$ of test (Egger's test) included zero, no significant bias occurred in the publication of the results (Table 3).

The estimated OR for chromosomal disorders in infants con- ceived by ART was $1.14(95 \% \mathrm{Cl}, 0.90$ to 1.44$)$, which was not statistically significant. This means that infants conceived through ART are at $14 \%$ increased risk of chromosomal disorders than other infants that was not statistically significant. The results partly reflect the heterogeneity of the studies 
Table 3. Results of the meta-analysis of the odds of musculoskeletal abnormalities and chromosomal abnormalities in ART infants

\begin{tabular}{|c|c|c|c|}
\hline Studies & Adjusted OR (95\% CI) & Logarithm of OR & Articles' weight (\%) \\
\hline \multicolumn{4}{|l|}{ Musculoskeletal abnormalities } \\
\hline Klemetti et al. 2005 [9] & $1.55(1.05,2.27)$ & 0.38 & 12.13 \\
\hline El-Chaar et al. 2009 [14] & $1.54(0.48,4.94)$ & -0.41 & 1.69 \\
\hline Pinborg et al. 2010 [15] & - & 0.19 & 12.98 \\
\hline Seggers et al. 2015 [18] & - & -0.21 & 8.54 \\
\hline Jwa et al. 2015 [19] & $0.82(0.58,1.14)$ & -0.20 & 10.99 \\
\hline Wen et al. 2010 [22] & $0.59(0.24,1.54)$ & -0.07 & 4.17 \\
\hline Hansen et al. 2012 [24] & $1.75(1.30,2.35)$ & 0.61 & 12.45 \\
\hline Heisey et al. 2015 [25] & - & 0.33 & 6.87 \\
\hline Davies et al. 2012 [27] & $1.26(1.06,1.50)$ & 0.45 & 13.84 \\
\hline Halliday et al. 2010 [28] & - & 0.71 & 8.48 \\
\hline Sagot et al. 2012 [31] & $1.90(1.00,3.80)$ & 0.79 & 7.84 \\
\hline \multirow[t]{2}{*}{ Total OR and 95\% Cl (pooled) } & & $1.35(1.12,1.64)$ & \\
\hline & & $\begin{array}{c}\text { Heterogeneity }\left(\tau^{2}\right): 0.06 \\
\chi^{2}: 34.93(\mathrm{df}=10) ; p<0.01 ; I^{2}=74.06 \% \\
\text { Testing the total effect of } Z: 3.08(p<0.01) \\
\text { Begg's test: } Z=0.54(p=0.59) \\
\text { Egger's test: } t=0.79 ; p=0.45 ; 95 \% \mathrm{Cl}=-3.74,1.80\end{array}$ & \\
\hline \multicolumn{4}{|l|}{ Chromosomal abnormalities } \\
\hline Klemetti et al. 2005 [9] & - & 0.16 & 9.13 \\
\hline Pinborg et al. 2010 [15] & - & 0.13 & 6.72 \\
\hline Jwa et al. 2015 [19] & $0.92(0.71,1.20)$ & -0.10 & 14.27 \\
\hline Kelley-Quon et al. 2013 [20] & $0.31(0.15,0.63)$ & -0.91 & 7.44 \\
\hline Wen et al. 2010 [22] & $0.82(0.19,3.52)$ & -0.36 & 2.57 \\
\hline Hansen et al. 2012 [24] & $1.89(1.00,3.60)$ & 0.71 & 11.47 \\
\hline Heisey et al. 2015 [25] & - & 0.29 & 7.16 \\
\hline Davies et al. 2012 [27] & $0.82(0.55,1.21)$ & 0.26 & 11.75 \\
\hline Halliday et al. 2010 [28] & - & 0.02 & 13.57 \\
\hline Källén et al. 2010 [30] & $0.98(0.70,1.37)$ & 0.20 & 12.56 \\
\hline Sagot et al. 2012 [31] & $3.10(0.60,13.10)$ & 1.1 & 3.35 \\
\hline \multirow[t]{2}{*}{ Total OR and 95\% Cl (pooled) } & & $1.14(0.90 .1 .44)$ & \\
\hline & & $\begin{array}{c}\text { Heterogeneity }\left(\tau^{2}\right): 0.08 \\
\chi^{2}: 27.93(\mathrm{df}=10) ; p=0.002 ; I^{2}=64.2 \% \\
\text { Testing the total effect of } \mathrm{Z}: 1.1(p=0.27) \\
\text { Begg's test: } Z=0.3(p=0.82) \\
\text { Egger's test: } t=0.36 ; p=0.73 ; 95 \% \mathrm{Cl}=-2.27,3.14\end{array}$ & \\
\hline
\end{tabular}

ART, assisted reproductive technology; OR, odds ratio; $\mathrm{Cl}$, confidence interval.

$\left(\chi^{2}=27.93 ; p=0.002 ; I^{2}=64.2 \%\right)$, but since the $\mathrm{Cl}$ of test (Egger's test) included zero, no significant bias occurred in the publication of the results (Table 3 ).

\section{DISCUSSION}

Systematic review and meta-analysis of results of studies indicated that the risk of congenital malformations in infants conceived by ART increases, compared with infants of spontaneous conception ( $\mathrm{SC} ; \mathrm{OR}, 1.53 ; 95 \mathrm{Cl}, 1.37$ to 1.70 ) that was statistically significant; meaning that infants conceived by ART are at $53 \%$ greater risk for congenital malformations. The results of the study by Shevell and colleagues [32] showed that abnormalities were more in IVF group than SC. Simpson [1] suggested that the use of ART are associated with a relative increase in birth defects (OR, 1.30). The meta- analysis by Hansen and Bower [40] on systematic reviews and meta-analysis studies on ART and birth defects showed that the results of six studies indicated an increase of $30-70 \%$ (OR, 1.31 to 1.70 ) in birth defects in the ART group. In the meta-analysis study by 
Pandey and colleagues [41], the OR of congenital malformations in ART infants was estimated $1.67(95 \% \mathrm{Cl}, 1.33$ to 2.09$)$. The results of the study by Jie et al. [42] indicated no significant differences between the two groups of ART and SCs regarding the prevalence of birth defects $(p=0.07)$. In the metaanalysis by Hansen et al. [43] on 45 studies, the OR of congenital malformations in infants conceived through ART was 1.32 (95\% Cl, 1.24 to 1.42) and in ART twin infants was 1.11 (95\% $\mathrm{Cl}, 0.98$ to 1.26$)$, which was not statistically significant.

In the present study, the results significantly showed that infants conceived by ART are $89 \%$ more born with low weight (OR, 1.89; $95 \% \mathrm{Cl}, 1.36$ to 2.62). The results by Jamshidi et al. [44] suggested that $1 \%$ of singleton SCs were LBW, compared with $19 \%$ in singleton IVF group, with a statistically significant OR of 2.5; while, the research by Hajishafiha and colleagues [45] showed that the growth parameters and fetal development including birth weight was not statistically different between two groups of users of ART methods and SC. In the research by Yasaei and Ataei [46] birth weight and gestational age in three groups of spontaneous twin pregnancies, after IVF, and ovulation induction had no significant differences. The OR estimated in the meta-analysis of results by Helmerhorst et al. [47], Jackson et al. [48], McDonald et al. [49], and Pandey et al. [41] have reported LBW in ART group, compared to spontaneous pregnancies, $\mathrm{OR}, 1.7 ; 95 \% \mathrm{Cl}, 1.5$ to $1.9 ; \mathrm{OR}$, $1.8 ; 95 \% \mathrm{Cl}, 1.4$ to $2.2 ; \mathrm{OR}, 1.6 ; 95 \% \mathrm{Cl}, 1.3$ to 2.0 ; and $\mathrm{OR}, 1.67$ $95 \% \mathrm{Cl}, 1.6$ to 1.8 , respectively.

The results of the current meta-analysis on conception following ART indicated that these infants $(\mathrm{OR}, 1.79 ; 95 \% \mathrm{Cl}, 1.21$ to 2.63$)$, compared with normal pregnancies, have $79 \%$ more preterm labor that was statistically significant. Barat et al. [37] concluded in their study that the mean age in the group receiving ART were lower, compared with SC, but was not statistically significant.

Regarding the results of the meta-analysis on the likelihood of preterm labor in ART, compared with spontaneous pregnancies, Helmerhorst et al. [47] estimated the $2.0(95 \% \mathrm{Cl}, 1.8$ to 2.3$)$; Jackson et al. [48] $2.0(95 \% \mathrm{Cl}, 1.7$ to 2.2$)$; McGovern et al. [50] $2.0(95 \% \mathrm{Cl}, 1.8$ to 2.2); McDonald et al. [49] $1.8(95 \% \mathrm{Cl}$, 1.5 to 2.2$)$; and Pandey et al. [41] $1.5(95 \% \mathrm{Cl}, 1.5$ to 1.6$)$; these results were all significant and were almost similar to the results of the current meta-analysis.

Regarding the risk of major malformations (cardiovascular, central nervous system, musculoskeletal, urogenital and chromosomal abnormalities) in infants after ART, compared with
SCs, the meta-analysis of the results indicated that infants conceived by ART were $43 \%$ more susceptible to cardiovascular abnormalities $1.43(95 \% \mathrm{Cl}, 1.30$ to 1.60$)$ that was statistically significant. Among 14 studies, the OR was not only higher than one, but also statistically significant. In the meta-analysis by Wen et al. [51], the OR of births resulting from ART, compared with SC, was $1.64(95 \% \mathrm{Cl}, 1.30$ to 2.17$)$ that was statistically significant.

The results of the meta-analysis of the results of the central nervous system disorders suggested that infants conceived by ART develop this complication $36 \%$ more than infants conceived spontaneously $\mathrm{OR}=1.36(95 \% \mathrm{Cl}, 1.10$ to 1.70$)$. Among 10 studies included in the current meta-analysis, only one case estimated the OR of birth of an infant with central nervous system less than one and was in four studies not only higher than one, but also statistically significant. In the meta-analysis by Wen et al. [51] the likelihood of birth of an infant with central nervous system abnormalities in ART users, compared with SC, was estimated at $2.0(95 \% \mathrm{Cl}, 1.3$ to 3.2$)$ that was statistically significant.

Regarding urogenital abnormalities, the results indicated that the probability of ART infants born with these abnormalities, compared with SCs, was 58\% (OR, 1.58; $95 \% \mathrm{Cl}, 1.28$ to 1.94), more statistically significant. From 13 studies included in the meta-analysis, only one cases [19] declared an OR of less than one regarding the probability of urogenital abnormalities in ART infants and 4 studies reported higher OR that were statistically significant. A meta-analysis conducted by Wen and colleagues [51] also reported the chance of having a baby with urogenital malformations in ART group OR=1.6 $(95 \% \mathrm{Cl}$, 1.3 to 2.1 ) that was statistically significant and is close to the OR estimated in the present study.

In the present meta-analysis, the risk of musculoskeletal disorders in infants receiving assisted reproductive therapy was $35 \%(\mathrm{OR}, 1.35 ; 95 \% \mathrm{Cl}, 1.12$ to 1.64$)$ higher than infants of SC. From eleven articles included in the meta-analysis, 7 articles reported a statistically significant OR of higher than one regarding the risk of musculoskeletal disorders in ART infants. A meta-analysis by Wen et al. [51] also reported OR of 1.48 (95\% $\mathrm{Cl}, 1.09$ to 2.03 ) in this regard.

The results of the risk of chromosomal abnormalities in infants conceived by ART showed that these infants are born with $14 \%$ increased risk of chromosomal abnormalities than infants with $\mathrm{SC}(\mathrm{OR}, 1.14 ; 95 \% \mathrm{Cl}, 0.90$ to 1.44$)$, which was not statistically significant. Among eleven studies that were evalu- 
ated in the current meta-analysis, 4 studies reported an OR of less than one and only one that was statistically significant (The study by Hansen et al. [24] that estimated the possibility of having a baby with chromosomal abnormalities in infants using ART a little more than 2, compared to SCs).

The results of the current meta-analysis also indicated a remarkable discrepancy among studies that can be due to the method of assessing infants in case and control groups, as well as matching some confounding variables including mother's age, the reason and duration of infertility, previous treatments, exposure to some environmental factors, high-risk behaviors (smoking and alcohol), and variety of ART procedures. Some researchers have concluded that the increased risk associated with the use of ART should be sought more in couple's problems and the reason of infertility than infertility treatment.

European Society for Human Reproduction and Embryology reported on the status of patients after treatment that newborns after the use of ART methods such as IVF or ICSI are born with $40-50 \%$ more birth defects [52]. Similarly, an increased risk is reported in infertile couples conceiving spontaneously or with intervention after a long period of infertility. The main reason of this increased risk can be the genetic characteristics and special conditions occurring in couples, rather than the received treatment; it is thus suggested that future studies select the control group from infertile couples who have conceived spontaneously.

One of the most important individual effects on children's health following increased ART treatments is the chance of multiple pregnancies occurring following transferring more than one embryo. Total risk of multiple pregnancies demonstrably increases in women using ART. Notably, most of these pregnancies are dizygotic and as far as the adverse outcomes of monozygotic pregnancies are higher, this indicates the decreased possibility of congenital malformations in multiple pregnancies following ART, compared to SCs.

\section{CONCLUSION}

It is suggested that the future meta-analysis be conducted on more detailed factors, such as comparing ART with the possibility of birth of an abnormal infant or comparing the abnormalities in singleton pregnancies with multiple pregnancies or assess the infants' gender, in order to be able to select the safest treatment options for minimizing the risk of birth defects.

\section{CONFLICT OF INTEREST}

The authors have no conflicts of interest associated with the material presented in this paper.

\section{ORCID}

Hayedeh Hoorsan https://orcid.org/0000-0003-2960-8821

Parvin Mirmiran https://orcid.org/0000-0003-2391-4924

Shahla Chaichian https://orcid.org/0000-0001-5772-8711

Yousef Moradi https://orcid.org/0000-0002-2936-5930

Roza Hoorsan https://orcid.org/0000-0003-0537-5875

Fatemeh Jesmi https://orcid.org/0000-0003-0120-1835

\section{REFERENCES}

1. Simpson JL. Birth defects and assisted reproductive technologies. Semin Fetal Neonatal Med 2014;19(3):177-182.

2. Qin J, Sheng X, Wang H, Liang D, Tan H, Xia J. Assisted reproductive technology and risk of congenital malformations: a meta-analysis based on cohort studies. Arch Gynecol Obstet 2015;292(4):777-798.

3. Lu YH, Wang N, Jin F. Long-term follow-up of children conceived through assisted reproductive technology. J Zhejiang Univ Sci B 2013;14(5):359-371

4. Zollner U, Dietl J. Perinatal risks after IVF and ICSI. J Perinat Med 2013;41(1):17-22.

5. Kazem M, Ali A. An overview of the epidemiology of primary infertility in Iran. J Reprod Infertil 2009;10(3):213-216.

6. Yan Jl, Geng L.H, Zhong Y. Birth defects in assisted reproductive technology and spontaneously conceived children: a meta-analysis. J Reprod Contracept 2013;24(4):237-252.

7. Fortunato $A$, Tosti $E$. The impact of in vitro fertilization on health of the children: an update. Eur J Obstet Gynecol Reprod Biol 2011;154(2):125-129.

8. Henningsen AK, Pinborg A. Birth and perinatal outcomes and complications for babies conceived following ART. Semin Fetal Neonatal Med 2014;19(4):234-238.

9. Klemetti R, Gissler M, Sevón T, Koivurova S, Ritvanen A, Hemminki E. Children born after assisted fertilization have an increased rate of major congenital anomalies. Fertil Steril 2005; 84(5):1300-1307.

10. Hediger ML, Bell EM, Druschel CM, Buck Louis GM. Assisted reproductive technologies and children's neurodevelopmental outcomes. Fertil Steril 2013;99(2):311-317. 
11. Eldar-Geva T, Srebnik N, Altarescu G, Varshaver I, Brooks B, Levy-Lahad $\mathrm{E}$, et al. Neonatal outcome after preimplantation genetic diagnosis. Fertil Steril 2014;102(4):1016-1021.

12. Olson CK, Keppler-Noreuil KM, Romitti PA, Budelier WT, Ryan $G$, Sparks $A E$, et al. In vitro fertilization is associated with an increase in major birth defects. Fertil Steril 2005;84(5):13081315.

13. Källén B, Finnström $O$, Nygren KG, Olausson PO. In vitro fertilization in Sweden: child morbidity including cancer risk. Fertil Steril 2005;84(3):605-610.

14. El-Chaar D, Yang Q, Gao J, Bottomley J, Leader A, Wen SW, et al. Risk of birth defects increased in pregnancies conceived by assisted human reproduction. Fertil Steril 2009;92(5):15571561.

15. Pinborg A, Loft A, Aaris Henningsen AK, Rasmussen S, Andersen AN. Infant outcome of 957 singletons born after frozen embryo replacement: the Danish National Cohort Study 19952006. Fertil Steril 2010;94(4):1320-1327.

16. Fujii M, Matsuoka R, Bergel E, van der Poel S, Okai T. Perinatal risk in singleton pregnancies after in vitro fertilization. Fertil Steril 2010;94(6):2113-2117.

17. Wisborg K, Ingerslev HJ, Henriksen TB. In vitro fertilization and preterm delivery, low birth weight, and admission to the neonatal intensive care unit: a prospective follow-up study. Fertil Steril 2010;94(6):2102-2106.

18. Seggers J, de Walle HE, Bergman JE, Groen H, Hadders-Algra $M$, Bos ME, et al. Congenital anomalies in offspring of subfertile couples: a registry-based study in the northern Netherlands. Fertil Steril 2015;103(4):1001-1010.

19. Jwa J, Jwa SC, Kuwahara A, Yoshida A, Saito H. Risk of major congenital anomalies after assisted hatching: analysis of three-year data from the national assisted reproduction registry in Japan. Fertil Steril 2015;104(1):71-78.

20. Kelley-Quon LI, Tseng CH, Janzen C, Shew SB. Congenital malformations associated with assisted reproductive technology: a California statewide analysis. J Pediatr Surg 2013;48(6): 1218-1224.

21. Merlob P, Sapir O, Sulkes J, Fisch B. The prevalence of major congenital malformations during two periods of time, 19861994 and 1995-2002 in newborns conceived by assisted reproduction technology. Eur J Med Genet 2005;48(1):5-11.

22. Wen SW, Leader A, White RR, Léveillé MC, Wilkie V, Zhou J, et al. A comprehensive assessment of outcomes in pregnancies conceived by in vitro fertilization/intracytoplasmic sperm injection. Eur J Obstet Gynecol Reprod Biol 2010;150(2):160-
165.

23. Funke S, Flach E, Kiss I, Sándor J, Vida G, Bódis J, et al. Male reproductive tract abnormalities: more common after assisted reproduction? Early Hum Dev 2010;86(9):547-550.

24. Hansen M, Kurinczuk JJ, de Klerk N, Burton P, Bower C. Assisted reproductive technology and major birth defects in Western Australia. Obstet Gynecol 2012;120(4):852-863.

25. Heisey AS, Bell EM, Herdt-Losavio ML, Druschel C. Surveillance of congenital malformations in infants conceived through assisted reproductive technology or other fertility treatments. Birth Defects Res A Clin Mol Teratol 2015;103(2):119-126.

26. Reefhuis J, Honein MA, Schieve LA, Correa A, Hobbs CA, Rasmussen $\mathrm{SA}$, et al. Assisted reproductive technology and major structural birth defects in the United States. Hum Reprod 2009;24(2):360-366.

27. Davies MJ, Moore VM, Willson KJ, Van Essen P, Priest K, Scott H, et al. Reproductive technologies and the risk of birth defects. N Engl J Med 2012;366(19):1803-1813.

28. Halliday JL, Ukoumunne OC, Baker HW, Breheny S, Jaques AM, Garrett C, et al. Increased risk of blastogenesis birth defects, arising in the first 4 weeks of pregnancy, after assisted reproductive technologies. Hum Reprod 2010;25(1):59-65.

29. Ho CH, Peng FS, Chen HF, Lien YR, Chen SU, Yang YS. Twin pregnancies conceived by assisted reproductive technology: maternal and perinatal outcomes. Taiwan J Obstet Gynecol 2005;44(4):332-337.

30. Källén $B$, Finnström $O$, Lindam A, Nilsson E, Nygren KG, Otterblad PO. Congenital malformations in infants born after in vitro fertilization in Sweden. Birth Defects Res A Clin Mol Teratol 2010;88(3):137-143.

31. Sagot P, Bechoua S, Ferdynus C, Facy A, Flamm X, Gouyon JB, et al. Similarly increased congenital anomaly rates after intrauterine insemination and IVF technologies: a retrospective cohort study. Hum Reprod 2012;27(3):902-909.

32. Shevell T, Malone FD, Vidaver J, Porter TF, Luthy DA, Comstock $\mathrm{CH}$, et al. Assisted reproductive technology and pregnancy outcome. Obstet Gynecol 2005;106(5 Pt 1):1039-1045.

33. Yang H, Choi YS, Nam KH, Kwon JY, Park YW, Kim YH. Obstetric and perinatal outcomes of dichorionic twin pregnancies according to methods of conception: spontaneous versus in-vitro fertilization. Twin Res Hum Genet 2011;14(1):98-103.

34. Malchau SS, Loft A, Larsen EC, Aaris Henningsen AK, Rasmussen $\mathrm{S}$, Andersen AN, et al. Perinatal outcomes in 375 children born after oocyte donation: a Danish national cohort study. Fertil Steril 2013;99(6):1637-1643. 
35. Bonduelle M, Wennerholm UB, Loft A, Tarlatzis BC, Peters C, Henriet $S$, et al. A multi-centre cohort study of the physical health of 5-year-old children conceived after intracytoplasmic sperm injection, in vitro fertilization and natural conception. Hum Reprod 2005;20(2):413-419.

36. Adler-Levy Y, Lunenfeld E, Levy A. Obstetric outcome of twin pregnancies conceived by in vitro fertilization and ovulation induction compared with those conceived spontaneously. Eur J Obstet Gynecol Reprod Biol 2007;133(2):173-178.

37. Barat SH, Basirat Z, Bouzari Z, Yazdani SH, Zarin KR. Comparison of perinatal outcomes of twin births conceived using assisted reproduction technology versus spontaneous. J Babol Univ Med Sci 2009;11(2):49-53.

38. Zwink N, Jenetzky E, Hirsch K, Reifferscheid P, Schmiedeke E, Schmidt $D$, et al. Assisted reproductive techniques and risk of exstrophy-epispadias complex: a German case-control study. J Urol 2013;189(4):1524-1529.

39. Farhangniya M, Dortaj Rabori E, Mozafari Kermani R, Haghdoost AA, Bahrampour A, Bagheri P, et al. Comparison of congenital abnormalities of infants conceived by assisted reproductive techniques versus infants with natural conception in Tehran. Int J Fertil Steril 2013;7(3):217-224.

40. Hansen M, Bower C. The impact of assisted reproductive technologies on intra-uterine growth and birth defects in singletons. Semin Fetal Neonatal Med 2014;19(4):228-233.

41. Pandey S, Shetty A, Hamilton M, Bhattacharya S, Maheshwari A. Obstetric and perinatal outcomes in singleton pregnancies resulting from IVF/ICSI: a systematic review and meta-analysis. Hum Reprod Update 2012;18(5):485-503.

42. Jie Z, Yiling D, Ling Y. Association of assisted reproductive technology with adverse pregnancy outcomes. Iran J Reprod Med 2015;13(3):169-180.

43. Hansen M, Kurinczuk JJ, Milne E, de Klerk N, Bower C. Assisted reproductive technology and birth defects: a systematic review and meta-analysis. Hum Reprod Update 2013;19(4):330353.

44. Jamshidi R, Neisani Samani L. Comparison of pregnancy out- comes in primigravida women with infertility treatment ones at spontaneous pregnancies admitted to three hospitals in Tehran-1391. J Urmia Nurs Midwifery Fac 2014;12(7):506-514.

45. Hajishafiha M, Kiarang N, Tayeb Gasemi J, Shahbazi Z, Asadi N, Oshnoue S. Comparison between growth development of children conceived by ICSI and children conceived natural pregnancy. J Urmia Univ Med Sci 2014;24(11):922-926.

46. Yasaei FA, Ataei M. Perinatal outcomes of twin pregnancies obtained after in vitro fertilization: comparison with twin pregnancies obtained spontaneous or after ovarian stimulation. Ann Mil Health Sci Res 2008;6(1):83-86.

47. Helmerhorst FM, Perquin DA, Donker D, Keirse MJ. Perinatal outcome of singletons and twins after assisted conception: a systematic review of controlled studies. BMJ 2004;328(7434): 261.

48. Jackson RA, Gibson KA, Wu YW, Croughan MS. Perinatal outcomes in singletons following in vitro fertilization: a metaanalysis. Obstet Gynecol 2004;103(3):551-563.

49. McDonald SD, Han Z, Mulla S, Murphy KE, Beyene J, Ohlsson A, et al. Preterm birth and low birth weight among in vitro fertilization singletons: a systematic review and meta-analyses. Eur J Obstet Gynecol Reprod Biol 2009;146(2):138-148.

50. McGovern PG, Llorens AJ, Skurnick JH, Weiss G, Goldsmith LT. Increased risk of preterm birth in singleton pregnancies resulting from in vitro fertilization-embryo transfer or gamete intrafallopian transfer: a meta-analysis. Fertil Steril 2004;82(6): 1514-1520.

51. Wen J, Jiang J, Ding C, Dai J, Liu Y, Xia Y, et al. Birth defects in children conceived by in vitro fertilization and intracytoplasmic sperm injection: a meta-analysis. Fertil Steril 2012;97(6): 1331-1337.

52. European IVF-Monitoring Consortium (EIM); European Society of Human Reproduction and Embryology (ESHRE), Kupka MS, D'Hooghe T, Ferraretti AP, de Mouzon J, et al. Assisted reproductive technology in Europe, 2011: results generated from European registers by ESHRE. Hum Reprod 2016;31(2):233248. 